\title{
Are Innovation Output and Economic Output Strongly Related in Emerging Industrial Clusters? Evidence from China
}

\author{
Yingbo Li, PhD \\ Associate Professor of School of Public Policy and Management, \\ Tsinghua University, China \\ Yan Li, PhD \\ Associate Professor of School of Commerce, \\ Shandong University at Weihai, China \\ Zhen Lei, PhD \\ Associate Professor of Energy and Environmental Economics, \\ Penn State University,USA \\ Qiuya Liu, MA
}

School of Public Policy and Management, Tsinghua University, China

Doi:10.19044/esj.2018.v14n22p255 URL:http://dx.doi.org/10.19044/esj.2018.v14n22p255

\begin{abstract}
For many countries, innovation-driven development has become a prevalent consensus because innovation can effectively stimulate economic growth. Emerging industries are innovation-intensive with high potential economic benefit. However, is it assured that high innovation output means high economic benefit? In October of 2010, China State Council initiated the Decision of Speeding up Cultivation and Development of Strategic Emerging Industries, signifying top-down policy mobilization to advance emerging industries. According to seven types of emerging industries defined in the Decision, we collected data from official industrial databases to figure out spatial divergence of emerging industries in terms of innovation output and economic benefit over the years from 2000 to 2011. We construct twodimension scatter diagrams based on number of granted patents as the indicator of innovation output and industrial locational quotient as the indicator of industrial economic benefit. The result shows that China has seen preliminary spatial clustering of key emerging industries across regions and industries in the light of innovation output and economic benefit. However, not all regions with high innovation output have high economic benefit. The spatial divergence is closely related to region-specific and industry-specific
\end{abstract}


characteristics. We offer policy implications to facilitate targeted emerging industries with more detailed policy and regional endowment.

Keywords: Emerging industry; industrial performance; innovation; cluster

\section{Introduction}

Emerging industries are innovation-intensive, ranging from technology change and new service offerings to market exploitation. Emerging industries can either be those where a technology exists but the corresponding downstream value chain is unclear, or a new technology may subvert the existing value chain to satisfy existing customer needs (Lim, Platts and Minshall, 2013). Emerging industries are comprised of both new and diversifying firms (York and Lenox, 2014). The heterogeneity in strategies (Mitchell, 1989); and performance of entrepreneurial start-ups and diversifying incumbents during industrial emergence has become a classic theme of the strategic management literature (Ganco, 2009).

Many studies focus on innovation and economic growth. (Malerba and Orsenigo, 1996; Galindo \& Méndez, 2014). Recent studies demonstrated a close connection between patents and economic success (Westmore, 2013; Frietsch, 2014). Specific innovation-driven technological advance is the key to the growth of an economy and industry (Kuznets,1971; Solow,1956, 1957). Pasinetti (1993) contends that a production unit employs a trial-and-error method to make a series of refined decisions to adopt innovations and increase output levels. However, at the country level, technology change is maybe contributive to productivity growth rather than to economic efficiency (Benjamin and Winston, 2016).

Actually, if emerging industries are well associated with technological progress, then does high innovation output necessarily lead to high economic benefit? In the long run, the evolutionary approach embraces positive correlation between innovation and economic growth (Rajshree, 1998; David and Max, 2004; Uyarra, 2010). However, whether the correlation materializes shortly after promulgating encouraging policies is uncertain. In our paper, based on spatial distributions of patents and economic output, we find there is no correlation between innovation output and economic output in the shortrun. Further, we discuss the factors that cause the non-correlation and provide policy implications to advance innovation and economic growth synchronously. 


\section{The performance of industrial clusters}

\subsection{The factors influencing the performance of regional emerging industries}

\subsubsection{Regional factor endowments}

Von Thünen's theory of agricultural location and Weber's theory of industrial location provide the theoretical basis for the impact of cost on industrial location. Christaller's central place theory states that the establishment of industrial centers in a specific geographic location and the development of a demand threshold that maintains the lowest purchasing power and resource consumption in peripheral regions will yield the most effective and comprehensive industrial development model for central regions. Krugman (1991) studies the spatial effects of industrial location selection. Porter (1998) believes that spatial proximity promotes information exchange between innovation enterprises and between vendors and customers, thus reducing costs.

Factor endowments are embedded into locations and are typically divided into natural resource endowments (geographic resources) and social resource endowments (manpower, capital, technology, regional policies, and market conditions). Factor endowments refer to necessary external conditions of social and economic development. On one hand, factor endowments guide the selection of industrial structures, development paths, and transition patterns. On the other hand, an industry's sensitivities reflect, to a certain extent, other industry characteristics, such as an industry's position in the domestic economy, its internal distribution structure, its development process, and problems associated with this process. Human capital is a key feature of new regional industrial development. The '2013 Global Manufacturing Competitive Index', which is jointly issued by Deloitte and the United States Council on Competitiveness, found labor innovation to be the key factor driving national manufacturing competitiveness, which refers to the quality and accessibility of scientists, researchers, engineers, and technical workers. In promoting emerging strategic industrial development, regions boasting strong factor endowments enjoy a 'first mover' advantage in the realm of industrial development. A region's factor endowment must match the extent and trajectory of emerging strategic industrial development to provide a solid basis for development while effectively avoiding risks.

\subsubsection{Industrial carrying capacity}

In the field of ecology, carrying capacity is defined as the "maximum amount of one species that the environment can support'( Gao, L. \& Zhang, H.Y. 2007) . Industrial carrying capacity thus refers to the new technologies. If the regional industrial capacity is exceeded, a region is unable to convert new technologies into new industries, even when new technologies present 
strong potential for future success. Industrial carrying capacity at the region level mainly refers to regional resource carrying capacity, regional innovation activity bearing capacity, and regional facilities capacity. Resource carrying capacity forms the basis of new industry cultivation. New industry development requires not only current industrial resources but also continuous investment in innovation resources.

New industries often require considerable investment over long payback periods due to the presence of high levels of uncertainty. Therefore, determination of whether a region possesses sufficient innovation resources and capacities has become a key question in the development of new industries. Regional innovation capacity refers to the integrated capacities of knowledge creativity, knowledge acquisition, enterprise innovation, innovation environments, and performance, among others. The 'Regional Innovation Capacity Report in China' suggested that China's regional innovation capacity is increasing overall, but that variation between regions is considerable, and especially for each index.

From this report, we can identify the strengths and weaknesses of each region and in turn determine the best means of improving regional innovation capacities. Strategic emerging industries must exhibit large intra-industry linkages, extensive commodity chains, and the capacity to meet major economic and social demands. However, uncertain market expectations regarding capacities to adapt to emerging technologies can be crippling. Therefore, regions presenting strong innovation capacities can offer resources and mechanisms required for the development of new industries.

\subsubsection{Regional market demand}

Market demands act as initial driving forces behind new industries; without considerable potential and real demand, a new industry is akin to a river without a source. The market structure of a new form of technology considers future market, supply and demand trends and the discrepancy between supply and demand. More specifically, in the case of subversive technique innovation, market scales must be adequately considered. The cost market school championed by Hoover (1936) and Isard (1960) states that the maximum profit principle is the main variable that affects an industrial region and that researchers must therefore attempt to study interactive relationships between costs and markets. Previous studies have suggested that when a market environment exhibits low degrees of complexity (mainly regarding the degree of heterogeneous information, competition, and development vitality), regional market positioning tends to be more evident (including customer and competitor positioning and coordination between organizational functions), and new technology production tends to be less pronounced while gradual innovation production is more prominent. In a more complex market 
environment, while regional market positioning is still evident, new technology production tends to be higher and gradual innovation production is not significantly evident.

\subsubsection{Regional industrial policy}

Significant differences exist between emerging strategic industries and traditional industry life cycles. The speed of emerging strategic industry development and decline is highly variable, and the life cycle of an emerging industry in a particular region may be shorter and present higher degrees of investing risk than those of traditional industries. Therefore, the cultivation and development of new regional industries requires not only the execution of high quality development forecasts but also the application of effective complementary policies. Traditional approaches to new industry development may lead to inefficient use of resources. Such approaches may also lead to shortsighted policies and the fragmentation of policy tools, inhibiting development across multiple regions. Moreover, development patterns in which 'policy markets' direct emerging regional industries may produce a dead zone of demand side policies. Therefore, the development of industrial policies that enable coordination between governments and markets is critical. Sociological researchers have noted that one of the most important factors affecting industrial location is regional policy. Therefore, it is necessary to identify appropriate government intervention measures that support regional economic development (Jiang, L.L., Wang, S.J. \& Feng, Z.X .2009).

\subsection{Regional clusters of emerging industries}

Geographic agglomerations, described as an 'industry concentrated in certain localities', have been recognized as an important characteristic of the industrial landscape (Marshall,1920). According to Marshall's definition, three important types of agglomeration externalities in clusters of similar firms include: (i) access to specialized labor, (ii) access to specialized inputs, and (iii) access to knowledge spillovers.

The revival of the cluster idea among economic geographers, sociologists and economists of innovation, follows from the influential work of Porter (1990) and the global fame of the Silicon Valley (Saxenian, 1994). Scholars have contributed a multiplicity of interpretations of the original concept, thus resulting in a certain degree of theoretical and empirical confusion (Martin and Sunley, 2003; Maskell and Kebir, 2006; Maskell and Malmberg, 2007). Agglomeration externalities are created by spatial concentration of groups of related firms. Well-known examples of regional concentrations of technology companies include semiconductor firms in Silicon Valley, biotechnology firms in San Diego, California or Cambridge, England, and software firms in Bangalore, India. These clustered firms reveal 
that 'the net benefits to being in a location together with other firms increases with the number of firms in the location' (Arthur, 1994), and these benefits may include greater access to specialized labor, specialized inputs, and knowledge spillovers.

Besides examining clustering tendencies through industrial activity, a number of empirical studies of geographic aggregation verified a positive relationship between agglomeration and firm performance. Firms that have larger industrial value will tend to have more knowledge stocks (Cohen and Levinthal, 1990). DeCarolis and Deeds (1999) demonstrated a positive relationship between US biotechnology firms' IPO valuations and a measure of the richness of the firms' locations. However, Folta, T. B., Cooper, A. C., \& Baik, Y. S. (2006) found no association between the size of clusters and rates of initial public offerings for biotech firms.

Based on prior work we provide evidence of a link between regional cluster and industrial performance. One report from PriceWaterhouseCoopers on emerging industries sheds light on key assumptions and related approaches for classifying emerging industries. It stresses four aspects: firm capital raising data, cross-sector investment data, firm patenting data and sector growth potential. Oschlies (2013) provides performance consequences of emerging industries in terms of financial and strategic management. We develop Oschlies's thoughts and offer a performance-measuring framework for emerging industries (See Figure 1). Our work is focused on the evaluation of innovation output and economic benefit.

\section{The development of emerging industries in China}

In Oct. 2010, the State Council of China promulgated the 'Decision to speed up cultivation and development of strategic and emerging industries.' (We denote this The Decision). It was a sign of the launching of a top strategy to promote emerging industries with formal institutional arrangements. According to the decision, China's emerging industries include energy-saving and environmental protection, bio-pharmacy, alternative energy, new materials, new energy vehicles, high-end equipment and new-generation IT. China's central government hopes to fuel the new engine for economic prosperity by way of developing emerging industries.

Within appropriate top-down policy incentives, industrial clusters of emerging industries are taking root in localities. Burgeoning small firms, for example, XIAOMI which is specialized in smart and flexible electronic production, became very competitive in market niches. R\&D-linking enterprises, for instance, Beijing Genomics Institute, turned into the world's largest genome sequencing and analysis center. Until 2015, emerging industries covered 27 key sectors; incomes of large-scale enterprises amounted to16.9 trillion RMB Yuan which accounted for $15.3 \%$ of overall 
industrial incomes, increased by $3.4 \%$ yearly. From 2010 to 2015, enterprise revenues of emerging industries increased at an annual growth rate of $17.8 \%$. In 2015, the economic outputs of emerging industries in Shenzhen accounted for $40 \%$ of GDP and the total economic size was more than 2.3 trillion RMB Yuan. See Figure 1.

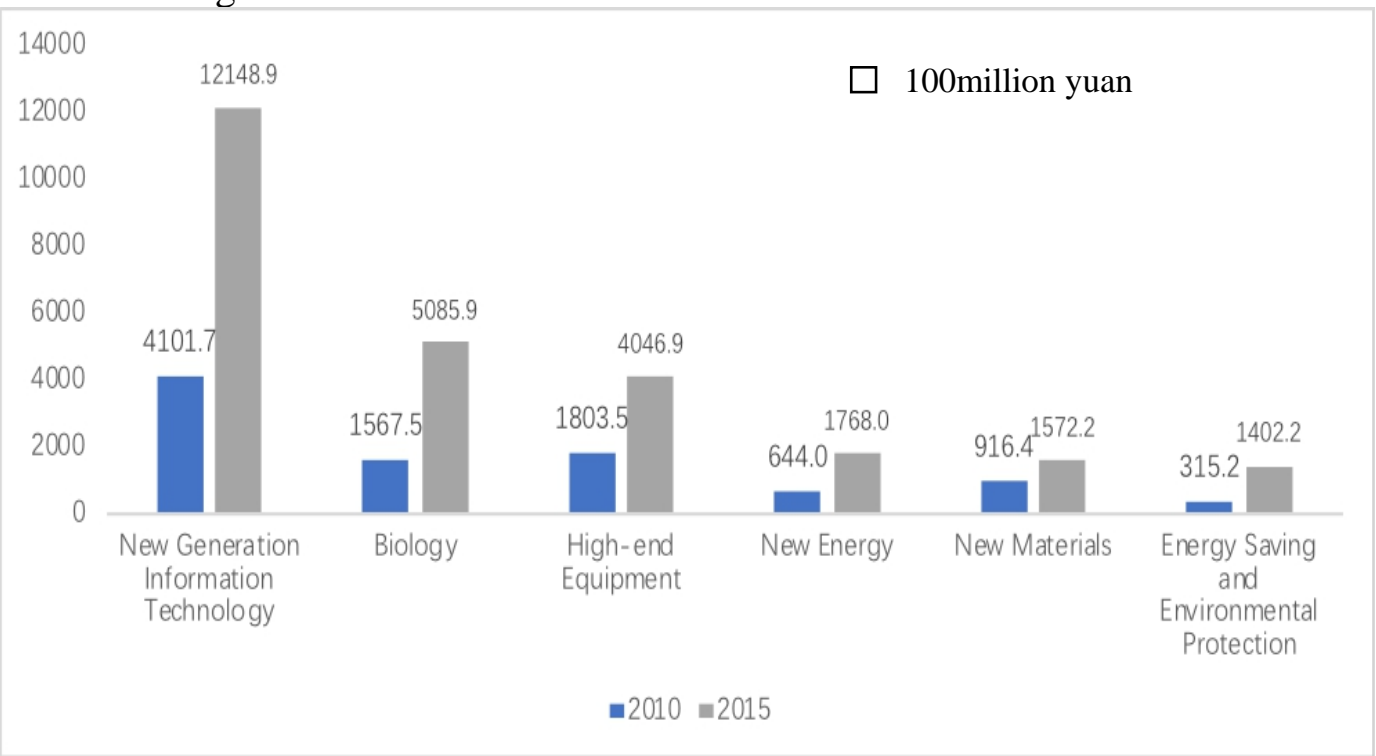

Figure 1 Sectoral performance of emerging industries in China during $12^{\text {th }}-$ Five-Plan

Local governments have exerted great influence on nurturing and boosting emerging industries. Most provinces in the mainland (except for Hong Kong, Macau, and Taiwan) have initiated relevant specific policies to boost emerging industries. Some local governments have issued full-scale plans for emerging industries in terms of seven classifications of the central government. Policy tools, including public funding, private financing, IPR protection, industrial demonstration, taxation incentives, prizes, and web databases, are getting closely involved in industrial acceleration. For example, electronic information, alternative energy vehicles and semiconductor lighting have reached roughly \$1.4 trillion in the Pearl River Delta up to 2013. Alternative energy, biomedicine, high-end equipment manufacturing, electronic information, and energy-saving and environmental protection in the Yangtze River Delta (i.e., Shanghai, Jiangsu, and Zhejiang) have reached above $\$ 2.8$ trillion. IT equipment, new materials, and aerospace generation in Beijing and Tianjin have reached $\$ 1$ trillion. Some central and western provinces obtained $\$ 2$ trillion and $\$ 0.5$ trillion, respectively. Some high-tech companies such as HUAWEI and ZHONGXING ranking among the world's leading integrated communication firms contributed a lot to IP production. See Figure 2. 


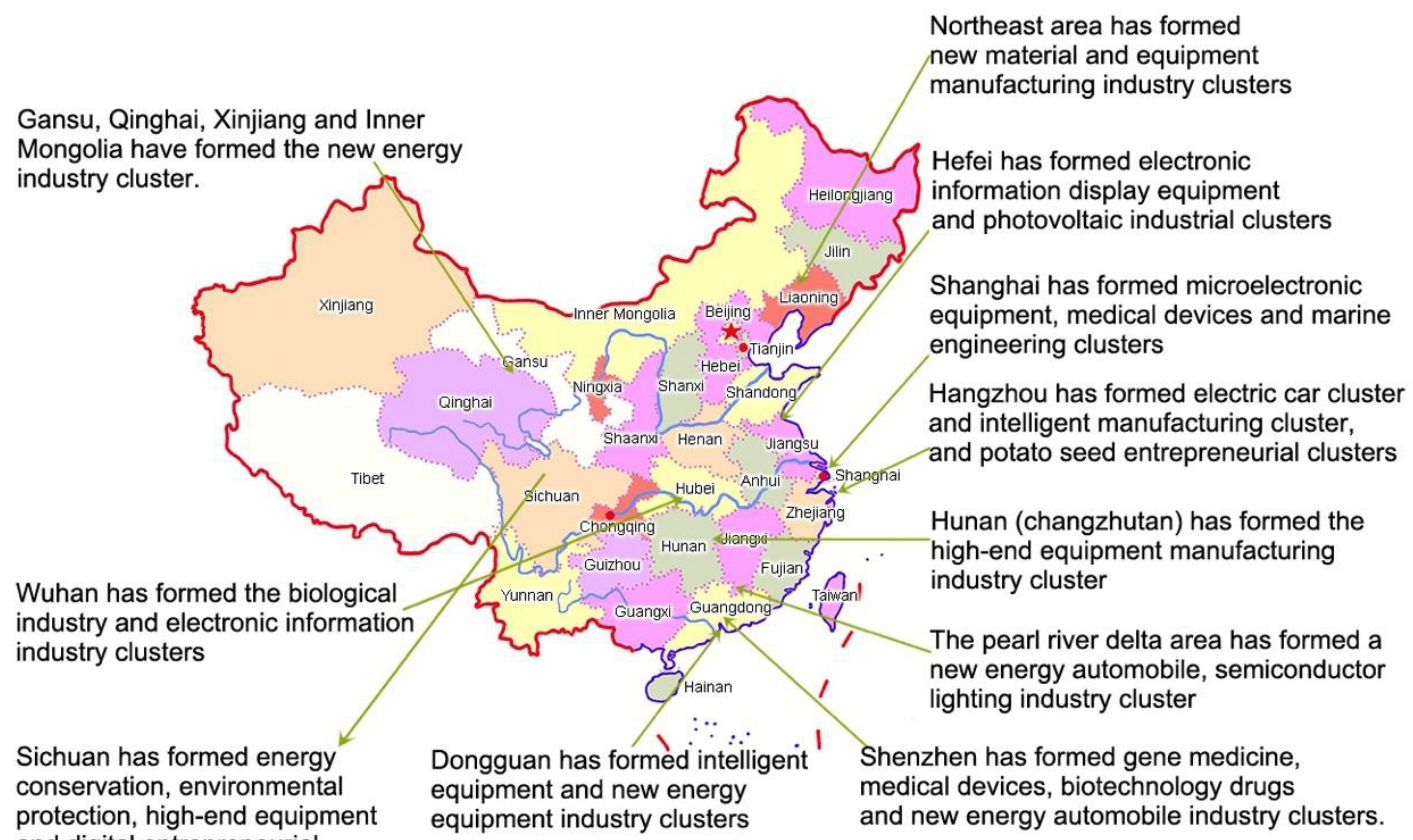
and digital entrepreneurial industry clusters

Figure 2 Typical regional clusters of emerging industries in China

Notably, there are still some obstacles hindering emerging industries. Market access barriers to emerging industries are a big issue for many small private firms, in particular telecommunications, broadcasting, television production and high-end equipment manufacturing industries. For example, without long-standing performance files, high-end equipment manufacturers are not able to benefit from risk-sharing with governments and customers in the domestic market. Public funds are more easily allocated to state-owned enterprises rather than private firms, which depresses the vitality of market players. Furthermore, the certification and authorization system of large-scale construction projects is too rigid to effectively spread to private firms, as in the case of Wind power . Institutional obstacles also exist in science-based industries. For example, the bio-pharmaceutical industry has yet to form a complete system of licensing, pricing and procurement of novel drugs and generic drugs.

On a regional scale, gaps in growth rate and quality of emerging industries still exist. Economic and social perspectives show great regional disparities in China; there is a need for coordination between national policy and targeted regional policy (Luo,X.L. \& Xu,J. 2015). Economic Imbalance 
across regions leads to uneven distribution in allocating innovation resources. Western provinces have difficulty in absorbing talented innovators and entrepreneurs.

\section{Methodology}

\subsection{Evaluation method}

\subsubsection{Measurements of industrial performance}

Cox (1974) holds that industrial performance is a very multidimensional issue, ranging from economic growth, innovation output and environmental protection to social welfare improvement. Aldrich et al. (1994) define an emerging industry as an 'industry in its formative years' that faces several constraints, including a generally high level of uncertainty about future outcomes for managers and stakeholders alike, the absence of technological as well as performance measurement standards, and the lack of external legitimacy. Performance in high-technology industries, such as biotechnology, is strongly related to the firms' underlying knowledge (McCann B T, Folta T B., 2011).

We might be unable see clearly the extent to which emerging industries in their nascent state are conducive to environmental protection or social welfare improvement. Moreover, data on environmental performance are more dispersed and the evaluation work seems to be very complicated (Thoresen, 1999). As for social welfare performance, it is difficult to construct an unimpeachable and standardized evaluation system (Cuesta-Gonza'lez et al., 2006). Therefore, two aspects of performance evaluation, evaluation of economic growth and innovation output, are widely addressed.

\subsubsection{Patents as measures of innovation output}

As an indicator of innovation output, patent counts have been widely adopted in innovation-related researches. Bessen (2005) holds that the patent system should operate as a means for the diffusion of technical information disclosed in inventions. The annual number of new patents is a typical measure of evaluating innovation output and science-technology linkages (STEP, 1997).

Patent statistics remain a unique resource for analysis of the process of technical change (Griliches, 1990). A patent grant is an intellectual property right granted by government. In the US, it is heavily influenced by the inefficiencies and constraints of the USPTO (Griliches, 1989). However, granted patents stand for high quality and usefulness, with official authentication.

Patent grant plays a role in the reach of the market for ideas. Drivas et al (2015) conclude that the patent grant effect varies across technology fields; the publicity associated with the patent grant is more important in shaping the 
geographic reach of patent transfers when patents originate from less innovative states (Drivas et al., 2015). Patenting activity provides a good performance proxy in young industries in which sales and profits may not be generated for a significant time during firms' developmental stages (Mccann B T, Folta T B., 2011). Johnson and Liu (2011) show, for the case of China, that technology markets enhance knowledge spillovers and innovation.

Emerging industries tend to be research and knowledge intensive industries, mostly driven by key enabling technologies, new business models such as innovative service concepts, and by societal challenges that industry must address as a matter of survival, e.g. climate change, the aging society, etc. Breitzman and Hicks (2008) noted that they share the common case of small firms playing a disproportionately large role in the development of emerging technologies. In fact, despite accounting for a mere $8 \%$ of all patents in the database, small firms contributed $24 \%$ of the patents of U.S. firms in emerging industry clusters. Furthermore, this report verifies that the comprehensiveness of patenting data could be used to identify and classify emerging industries in the early stages of their industry life-cycle. In the light of this empirical research, we adopt patent grant number as an indicator to evaluate regional industrial innovation outcomes.

\subsubsection{Location quotient as a measure of regional competitiveness of an industry}

Porter (1990) links competitiveness to productivity. The main findings of the literature on competitiveness of countries are applicable to the competitiveness of regions within a country (Budd \& Hirmus, 2004; Camagni, 2002; Gardiner, Martin, \& Tyler, 2004; Malecki, 2002). According to the IMD (2012) competitiveness measures 'Competitiveness analyses how nations and enterprises manage the totality of their competencies to achieve prosperity or profit'.

Dennison, S. R (1939) first introduced the location quotient to quantify industrial competitiveness across regions. It can reveal what makes a particular region 'unique' in comparison to the national average. Guimaraes et al. (2009) provides the first theoretical justification for using LQs to estimate industrial concentration by deriving the LQ from a probabilistic model based on an Ellison and Glaeser (1999) dartboard model of firm location.

Industry LQ is a way of quantifying how 'concentrated'an industry is in a region compared to a larger geographic area. Location quotient is a ratio that compares a region to a larger reference region according to some characteristic or asset. Suppose $\mathrm{X}$ is the amount of some asset in a region (e.g., manufacturing jobs), and $\mathrm{Y}$ is the total amount of assets of comparable types in the region (e.g., all jobs). $\mathrm{X} / \mathrm{Y}$ is then the regional 'concentration' of that 
asset in the region. If $\mathrm{X}^{\prime}$ and $\mathrm{Y}^{\prime}$ are similar data points for some larger reference region (like a state or nation), then the LQ or relative concentration of that asset in the region compared to the nation is $(\mathrm{X} / \mathrm{Y}) /\left(\mathrm{X}^{\prime} / \mathrm{Y}^{\prime}\right)$. In our study, we adopt regional added value of one industry as $\mathrm{X}$ and regional GDP as $Y . X^{\prime}$ is national added value of one industry and $Y^{\prime}$ is national GDP.

\subsection{Data sources}

PricewaterhouseCoopers argued that a classification scheme for emerging industries could not only provide a valuable tool to support the definition of better public policies, but offer a measure of the economic importance and value of the activities concerned. This can only be achieved if the proposed classification system can be related to existing statistical information systems. However, the definition and classification content of emerging industries still basically impact statistical work on measuring industrial performance.

In China, 'Strategic and Emerging Industries" (SEIs) is more widely used than "emerging industry" and officially accepted by governmental sectors in the light of its specific highlight on both radical innovation and societal impacts (USCBC, 2013)'. In 2010, 'The Decision' was officially issued by the Chinese State Council, spelling out measures ranging from higher fiscal expenditure to easier bank credit and other financing during the 12th five-year plan. In 2012, 'Development Plan of National Strategic Emerging Industries during the 12th Five-Year-Plan Period (2011-2015)' was initiated to further expound strategies and plans for boosting energy saving, next-generation information technology, biotechnology, high-end equipment manufacturing, new energy, new materials, and new energy vehicle industries. Chinese researchers have been doing much work on empirical analysis of emerging industries from a variety of perspectives (Zhang and Fan, 2014; Yang, 2014; Hu, 2014; Zhou, 2015; Yang etal., 2015).

There are three mainstream systems of classifying emerging industries. The first is the 'Classification Content of SEIs' published by the Ministry of Industry and Information Technology (MIIT), which includes 721 product types and divides emerging strategic industries into 34 major categories, 152 mid-level categories, 470 smaller categories, and 332 subclasses. The second system is the 'Classification of SEIs' published by the National Bureau of Statistics, which classifies emerging industries into 30 categories ( Liu et al., 2009), 102 mid-level categories, and 311 smaller categories. The third system is the 'Strategic Guiding Catalog for Key SEIs Products and Services' published by the National Development and Reform Commission (NDRC), including 139 major products and services for the top seven SEIs. In our paper, we adopt the second classification published by the National Bureau of Statistics in line with data availability, integrity and authority. We process data 
abiding by the rules of homogeneity, uniqueness and operability. Patent data for each industry come from 'Report of the SEIs Invention Patents Statistical Analysis'. The report was published by SIPO. Data on industries come from Macro-China-Industry Database (MCID). Due to the more than one-year lag in release of data, we collected the statistics in 2013, that is to say, the data in our study include data for 2011 and 2012.

\subsection{Analysis of results}

We employ Quantile mapping distribution level of seven SEIs' invention patent numbers at the provincial level (except for Hong Kong, Macau and Taiwan) (See Figure 3). Darker colors correspond with regions of higher output of utility patents. The two figures reveal that eastern coastal provinces are the main concentration areas of SEI utility patents. The figure also reports the distributional unevenness across industries as well as across regions. Nonetheless, some SEIs have notable increases in utility patent numbers during 2011 and 2012. Energy-saving and environmental protection, new and alternative energy and new-generation IT are the three typical cases of rapid annual changes.

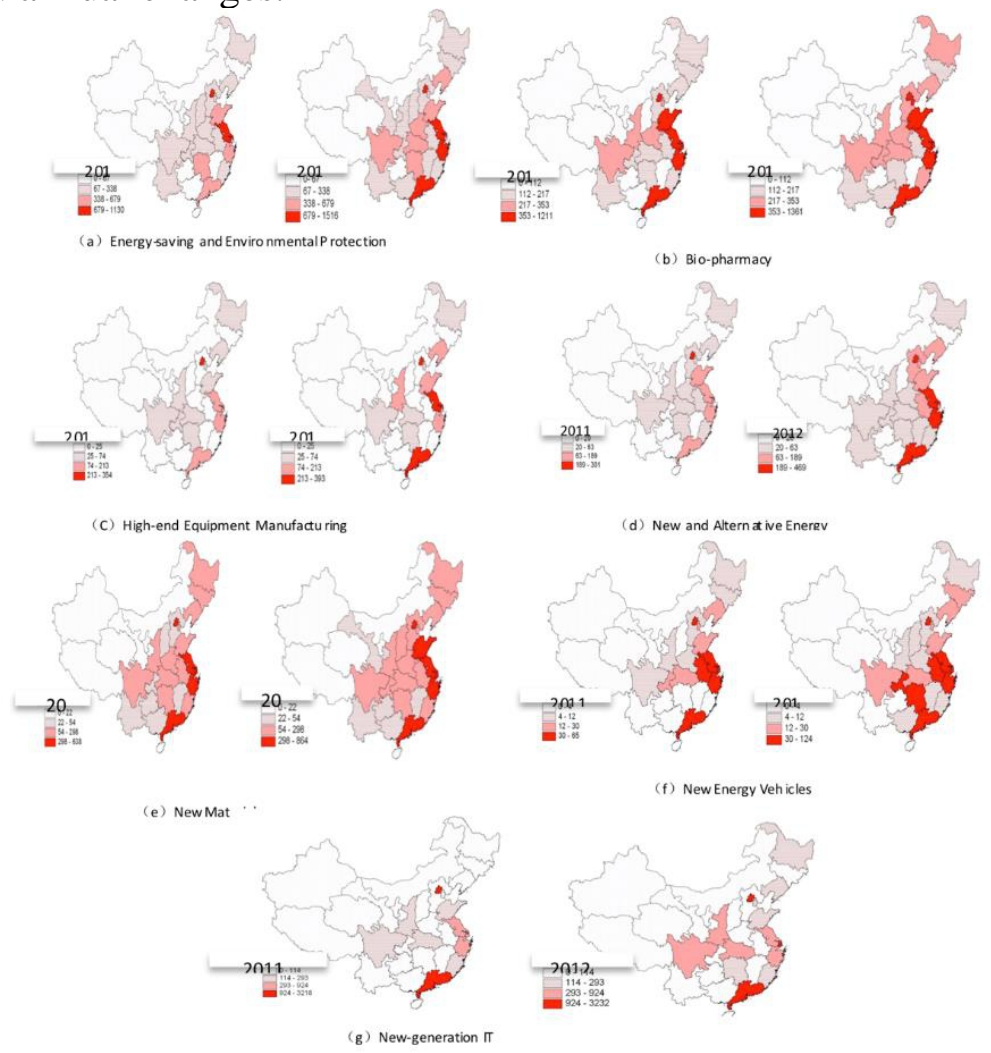

Figure3 Geographical cluster of Seven SEIs' Utility patents in 2011 and 2012 in Chinese Mainland (excluded Hongkong, Macao and Taiwan) 
In order to further detail the cluster characteristics of patent output, we adopt Moran's I to represent the degree of clustering. Five SEIs are spatially correlated. The outcome shows that regional cluster distribution of Moran's I did not change from 2011 to 2012. Furthermore, we report the regional cluster distribution for 2012 (See figure 4).

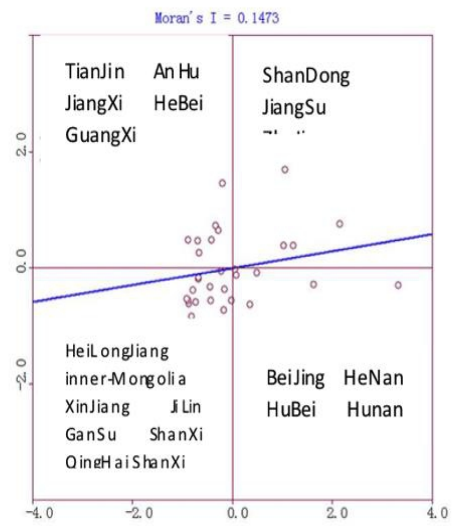

(a)Energy-saving and environmental protection

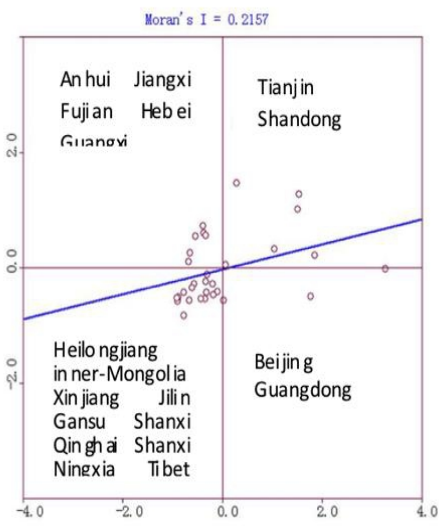

(b) Bio-ohamacv

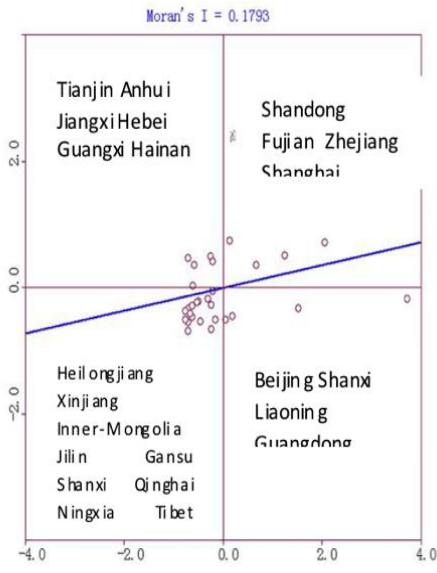

(c) New and al ternative en erg

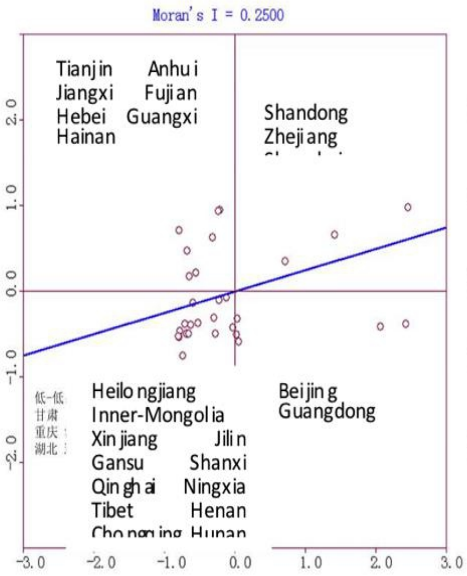

(d) New Materials

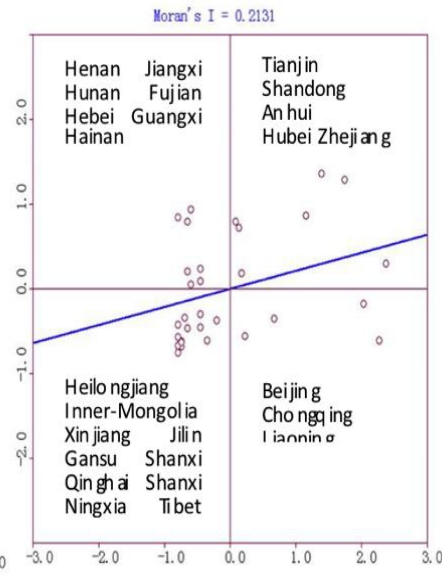

(e) New en ergy Vehicles

Figure 4 The spatial agglomeration of SEIs' utility patent output in 2012

Figure 4 reveals that Moran's I of utility patent number of each industry was significantly positive at the $1 \%$ level, denoting the presence of a positive spatial autocorrelation. The result shows that spatial cluster of innovation output across regions were not entirely randomized. Moran' I scatter plots for the four quadrants corresponded with the four types of local spatial connection between spatial units and adjacent areas. First is High-high agglomeration. The first quadrant represents high observed-value spatial units 
that are surrounded by high-value provinces. These provinces are endogenous development preferably and beneficial from the output of neighboring provinces.

According to the figures for various industries, the Shandong, Zhejiang, Shanghai, and Jiangsu provinces belong to the high-high agglomeration category. The Low-low agglomeration areas are located in the third quadrant. These provinces exhibit poor development and development potential. Three provinces of northeastern China (except for Liaoning province), the Chinese northern border provinces, and provinces in western China fall under this category. The third is Low-high distribution areas in the second quadrant. These regions (i.e., Tianjin, Hebei, Jiangxi, Fujian, Guangxi, and Hainan) generally achieve higher degrees of external innovation and development than peripheral provinces. The fourth is High-low distribution areas in the forth quadrant. These regions (i.e., Beijing, Guangdong, and Liaoning) represent growth poles of regional development that benefit from the output of neighboring provinces.

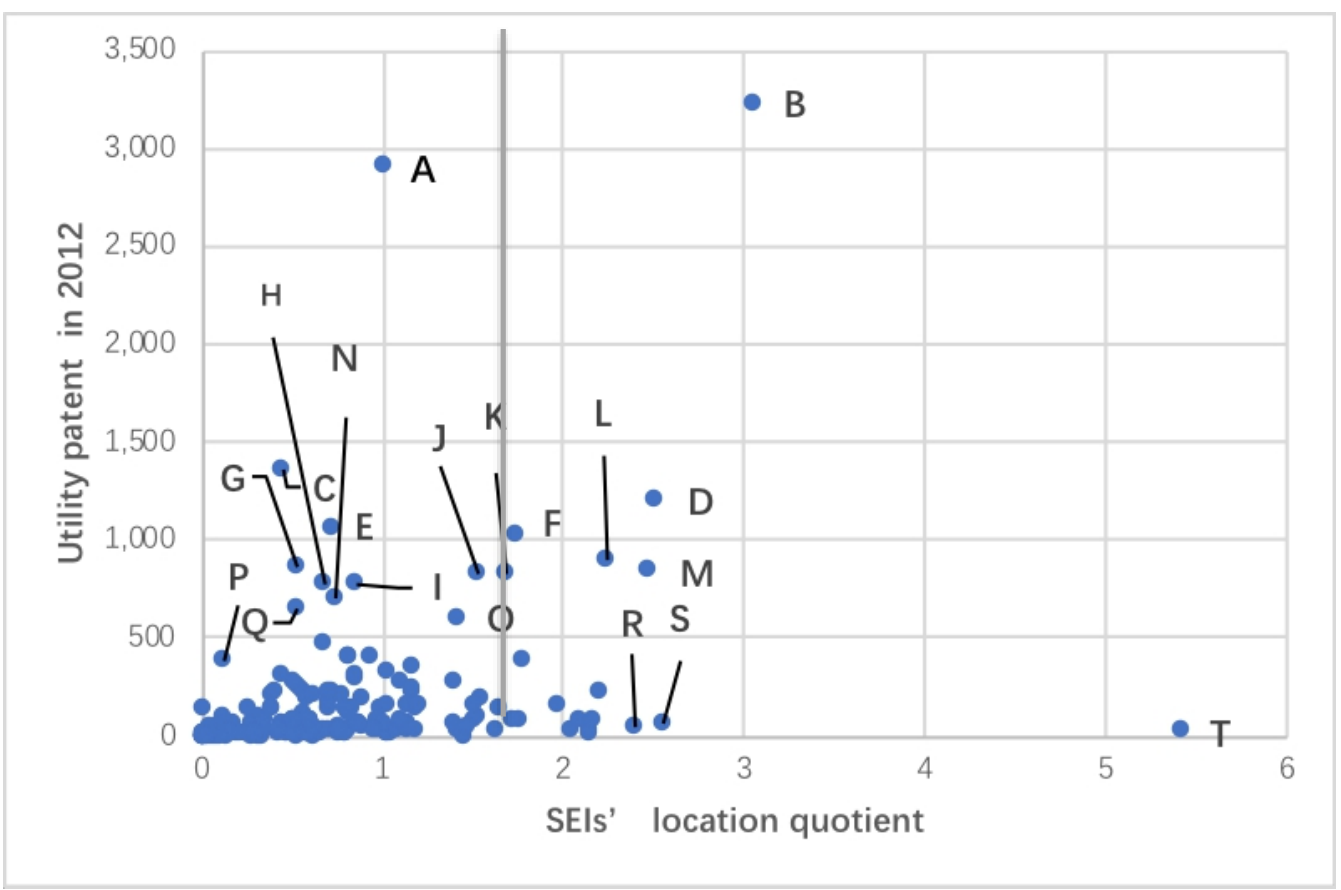

Figure 5 Spatial distribution of industries in provincial-level

A

B

C

$\mathrm{D}$

E

F

G

Beijing's New-generation IT

Guangdong's New-generation IT, SE

Beijing's Bio-pharmacy

Shanghai's New-generation IT, E

Guangdong's Bio-pharmacy, SE

Jiangsu's Bio-pharmacy, E

Guangdong's New material, SE 
Shanghai's New material, E Shanghai's Bio-pharmacy, E Jiangsu's New material, E Beijing's New material Shandong's Bio-pharmacy, E Jiangsu's New-generation IT,E Zhejiang's Bio-pharmacy, E Zhejiang's New material, E Shanxi's New-generation IT, M Zhejiang's New-generation IT, E Chongqing's New energy vehicle, SW Shanghai's New energy vehicle, E Jilin's New energy vehicle, NE

The regions where the quotient is bigger than 1.5 have significant industrial competitiveness. The regions where the patent number is bigger than 1000 have significant innovative competitiveness. In Figure 5, except for A and $\mathrm{B}$, other regions do not all reveal strong correlations between economic output and innovation output for all emerging industries. The result contradict the conclusion that positive coorelation between innovation and economic growth in the long run (Uyarra, 2010). However, for one specific industry, some regions show strong relations between innovation output and economic output.

\section{Conclusion and future outlook:}

The paper highlights spatial distribution characteristics of emerging industries in China. Based on statistical data of province-level, we evaluated the performance of emerging industries in terms of patent output and firm growth. The research outcome as a whole reveals the characteristics of spatial clustering for emerging industries. The paper finds that there is no significant relation between innovation output and economic output. To date, provinces in eastern China have better performance in emerging industries than provinces in western China. The reason mainly reflects the facts that eastern provinces invested more in $\mathrm{R} \& \mathrm{D}$ activities and market conditions, and are in addition connected with bountiful economic bases. However, regional convergence in developing emerging industries is noteworthy. Industrial specification, policy incentives and promotion patterns are homogeneous across regions. Some western provinces simply copy development modes adopted in eastern provinces regardless of regional endowments and actual demand. Therefore, western provinces fall behind, and resources are wasted. From the results of our research, some indicators of emerging industries report obvious spatial agglomeration in eastern areas. Even so, state-level and locallevel policy tools exert great influence in accelerating emerging industries. 
Industrial funds, demonstration projects, taxation incentives and demand stimuli are important features of governmental involvement. Future policy of local-level can target at activating the technological market, and the industrial R\&D lab and business model.

Measures of policy incentives intensity show that favorable policies are not as strong as firms really need. For instance, Tax deductions only relate to the direct R\&D cost of enterprises, which is far below actual R\&D expenses. The human cost relating to R\&D activies and service are not included in the tax deductions. Local protectionism in local investment in emerging industries limits effective resource flow across regions and may even cause cut-throat competition, resulting in convergence of regional emerging industries.

Our findings have implications for both research and practice. From a research perspective, they indicate that scholars should be aware of the need to consider additional measures of the richness of individual clusters beyond just the number of firms. Furthermore, they should consider potential moderators of this relationship, as it appears that particular firms may benefit more from clustering. This finding is of particular interest for a number of reasons. First, it points to the existence of asymmetries in the ability to develop knowledge-based competitive advantage through firm agglomeration. This competitive advantage will be particularly relevant in high-technology industries that require constant innovation to successfully compete. These findings also relate strongly to recent speculation about the potential for adverse selection in agglomerations (e.g., Shaver and Flyer, 2000). According to this view, those firms that are most likely to generate agglomeration externalities may want to avoid clustered locations because their relative advantage may suffer. Our results point to a countervailing force, namely that these very same firms may benefit more from clustering, raising the question of whether their relative advantage will in fact decline. From a practical perspective, our research informs both firm decision makers and policy makers. For those deciding whether to locate in an agglomeration or for those attempting to recruit firms to an agglomeration, it provides insights on which firms are most likely to benefit.

We employ provincial data to implement the research; however, data collection is very complicated and the timeline involves a lag. Based on the data used in this paper, we cannot fully judge the current situation of emerging industries. More importantly, evaluation work is closely related how to define and classify emerging industries, so the results basically manifest specific cases. The practices of developed economies also demonstrate that emerging industries are dynamically evolved with technological change, societal demand, institutional settings and even governmental decision-making patterns. Therefore, guiding principles for developing emerging industries appears universal, which needs to be deliberately studied regarding regional 
or industrial features We hope our work could help better understand China practice in emerging industries. Furthermore, the growth mechanisms and path selection of regional emerging industries, and linkages with regional innovation systems, are well worth discussing.

\section{Acknowledgement}

The authors thank the National Science Foundation of China (No. 71473142) for financial and intellectual support in the writing of this paper. This paper has benefited from many exchanges and much audience reaction. Any errors and all views expressed here are those of the authors.

\section{References:}

1. Agarwal R. (1998) . Evolutionary trends of industry variables. International journal of Organ, 16(4), 511-525.

2. Aldrich He, Fiol CM.(1994). Fools rush in - The institutional context of industry creation. Academy of Management Review, 19(4),645-67.

3. Arthur W. B. (1994). Positive feedbacks in the economy. Mckinsey Quarterly, 262(2), 81-94.

4. Beck, T. Kunt,A.D.\& Maksimovic,V.(2005). Financial And Legal Constraints To Firm Growth: Does Size Matter?. The Journal of Finance, 60(1), 137-177.

5. Benjamin B.M. Shao, Winston T. Lin.(2016).Assessing output performance of information technology service industries: Productivity, innovation and catch-up. Int. J. Production Economics, 172, 43-53.

6. Bessen,J.(2005).Patents and the diffusion of technical information. Economics Letters, 86(1), 121-128.

7. Board on Science, Technology, and Economic Policy (STEP).(1997). Industrial Research and Innovation Indicators. Washington, D.C. :National Academy Press.

8. Breitzman A., Hicks D.(2008).An Analysis of Small Business Patents by Industry and Firm Size. SBA Report.

9. Budd,L.\& Hirmis,A. (2004).Conceptual Framework for Regional Competitiveness. Regional Studies, 38(9),1015-1028.

10. Camagni, R. (2002). On the Concept of Territorial Competitiveness: Sound or Misleading?. Ersa Conference Papers.39, 2395-2411.

11. Cohen, W. M., \& Levinthal, D. A. (1990). Adsorptive capacity: a new perspective on learning. Administrative Science Quarterly, 35(1), 128152.

12. David A., Max K.(2004). Entrepreneurship and regional growth: an evolutionary interpretation. Journal of Evolutionary Economics14(5) ,605-616. 
13. Decarolis, D. M., \& Deeds, D. L. (1999). The impact of stocks and flows of organizational knowledge on firm performance: an empirical investigation of the biotechnology industry. Strategic Management Journal, 20(10), 953-968.

14. Dennison, S. R. (1939).Report on the Location of Industry in Great Britain. Political and Economic Planning, London.

15. Drivas, K., Fafaliou,I., Fampiou,E., Yannelis,D.(2015).The effect of patent grant on the geographic reach of patent trade. The Journal of High Technology Management Research, 26(1), 58-65.

16. Ellison, G. and Glaeser, E. L.(1999).Evolution of the Geographic Concentration of Industry. American Economic Review,89(2),311-16.

17. Folta, T. B., Cooper, A. C., \& Baik, Y. S. (2006). Geographic cluster size and firm performance. Journal of Business Venturing, 21(2), 217242.

18. Frietsch,R., Neuhäusler, P., Jung,T.\& Patent,B.V.L. (2014) Indicators for macroeconomic growth-the value of patents estimated by export volume. Technovation, 34, 546-558

19. Galindo M Á, Méndez M T. (2014). Entrepreneurship, economic growth, and innovation: Are feedback effects at work? Journal of Business Research, 67(5),825-829.

20. Ganco,M.(2009).Performance Differentials Between Diversifying Entrants And Entrepreneurial Start-Ups: A Complexity Approach. Academy of Management Review. 34(2), 228-252.

21. Gao, L., \& Zhang, H. Y. (2007). Progress in research of ecological carrying capacity. China Population Resources \& Environment, 17(2), $19-26$.

22. Gardiner B., Martin R. \& Tyler P..(2004).Head. Regional Studies,38(9).

23. Griliches,Z.(1989). Patent's: Recent Trends and Puzzles Brookings Pap. Econ. Act. Microeconomics, 291-330.

24. Griliches,Z.(1990) .Patent Statistics As Economic Indicators: A Survey. Journal of Economic Literature, 28(4), 1661-1707.

25. Guimaraes, P., Figueiredo, O., Woodward, D.(2009).Dartboard tests for the location quotient. Regional Science and Urban Economics.39(3), 360-364.

26. Hoover,E.(1936). The measurement of industrial localization. Review of Economics and Statistics,XVIII,162-171.

27. Hu,J.(2014).An empirical study on innovation efficiency of strategic emerging industry. Information Technology Journal. 13(3),548-53.

28. Isard,W.(1960).Methods of Regional Analysis.Cambriage,MA, MIT Press 
29. IMD(2012).IMD World Competitiveness Yearbook. Lausanne, Switzerland: IMD.

30. Jiang, L.L , Wang,S.J \& Feng, Z.X (2009). Construction of Regional Policy Framework under the Guidance of Regional Coordinated Development Strategy. World Geography Research. 2009 (02),56-63.

31. Johnson, W.H.A. \& Liu,Q. (2011). Patenting and the Role of Technology Markets in Regional Innovation in China: An Empirical Analysis. Journal of High Technology Management Research, 22(1), $14-25$.

32. Jorion,P.\& Talmor,E.(2001).Value Relevance of Financial and Non Financial Information in Emerging Industries: The Changing Role of Web Traffic Data. London Business School Accounting Subject Area Research Paper Series.

33. Kuznets, S. (1971). Modern economic growth: findings and reflections. American Economic Review, 63(3), 247-258.

34. Lim, S.Platts, K.Minshall, T.(2013).Market-pull and technology-push in manufacturing start-ups in emerging industries. Journal of Manufacturing Technology Management, 24(1),10-27. Liu, C.S. , Jian, Y.F., Chen,H. (2009).Impacts of different natural resource endowments on economic growth in different provinces of China. Resources Science, 6, 1051-1060.

35. Luo,X.L. \& Xu,J. (2015).Research on Regional Disparity and Its Influential Factors of Input-Output Coefficients. Procedia Computer Science.55, $175-185$.

36. Malecki, E. J.(2002). The economic geography of the internet's infrastructure. Economic Geography, 78(4), 399-424.

37. Marta de la Cuesta-Gonzá lez Maria Jesu s Mun oz-Torres Mar ia A'ngeles Ferna' ndez-Izquierdo.(2006).Analysis of Social Performance in the Spanish Financial Industry Through Public Data-A Proposal. Journal of Business Ethics,69(3), 289-304.

38. Marshall, A. (1920). Principles of economics: an introductory volume. Social Science Electronic Publishing, 67(1742), 457.

39. Martin, R., \& Sunley, P. (2003). Deconstructing clusters: chaotic concept or policy panacea?. Journal of Economic Geography, 3(1), 535.

40. Maskell, P., \& Kebir, L. (2006). What qualifies as a cluster theory? Druid Working Papers.

41. Maskell, P., \& Malmberg, A. (2007). Myopia, knowledge development and cluster evolution. Journal of Economic Geography, 7(7), 603-618.

42. Mccann B.T, Folta T.B., (2011).Performance differentials within geographic clusters. Journal of Business Venturing,26, 104-123. 
43. Mitchell, W. (1989).Whether and When? Probability and Timing of Incumbents' Entry into Emerging Industrial Subfields. Administrative Science Quarterly, 34(2), 208-230.

44. Myers, S.C.(1977). Determinants of corporate borrowing. Journal of Financial Economics, 5(2), 147-175.

45. Oschlies,M.K. (2013).Strategic Management in Emerging Industries: Evidence from the Renewable Energy Industry. Dissertation of The University of St. Gallen.

46. Pasinetti L L, Scazzieri R.(1993).Structural Economic Dynamics. Cambridge Books.

47. Pavitt,K.(1984). Sectoral patterns of technical change: Towards a taxonomy and a theory. Research Policy, 13(6) , 343-373.

48. Porter, M.(1990).The competitive advantage of nations. New York: The Free Press.

49. PriceWaterhouseCoopers.(2012). Emerging industries Report on the methodology for their classification and on the most active, significant and relevant new emerging industrial sectors. European Union.

50. Saxenian, A. (1994). High-tech dynamics. book reviews: regional advantage. culture and competition in Silicon Valley and route 128. Science, 264, 1614-1615.

51. Solow,R.M.(1956).A Contribution to the Theory of Economic Growth. Quarterly Journal of Economics, 70(1),65-94.

52. Solow,R.M.(1957).Technical Change and the Aggregate Production Function. Review of Economics \& Statistics, 39(3),554-562.

53. Cox. S.R.( 1974).An Industrial Performance Evaluation Experiment. The Journal of Industrial Economics, 22(3), 199-214.

54. Stulz, R.M., \& Williamson,R.(2003).Culture, Openness, and Finance. Journal of Financial Economics, 70(3), 313-349.

55. Thoresen, J.(1999).Environmental performance evaluation - a tool for industrial improvement. Journal of Cleaner Production, 7(5), 365370 .

56. US-China Business Council (USCBC). (2013).China's Strategic Emerging Industries: Policy, Implementation, Challenges, \& Recommendations.

57. Uyarra,E. (2010). What is evolutionary about 'regional systems of innovation'? Implications for regional policy. Journal of Evolutionary Economics, 20(1), 115-137.

58. Wang B.Q. \& Yang X.C. (2013).Analysis of the relationship between company's growth and its financial performance empirical evidence from the sample of listed companies of strategic emerging industries in Anhui Province. Journal of Applied Sciences, 13(18), 3857-3861. 
59. Westmore B. (2013). R\&D, Patenting and Growth: The Role of Public Policy. OECD Economics Department Working Papers.

60. Xue,Y. Gu,X.\&Wang Y.D.(2015).Research on the Impact of China's 'Independent Innovation Policy on Patent Licensing's Geographical Evolution in Strategic Emerging Industries. Eo-Informatics in Resource Management \& Sustainable Ecosystem Second International Conference. GRMSE 2014, Ypsilanti, MI, USA, October 3-5, 2014. Proceedings 2015,653-663.

61. Yang,C.(2014).Government policy change and evolution of regional innovation systems in China: evidence from strategic emerging industries in Shenzhen. Environment and Planning C: Government and Policy advance, Online publication.

62. York, J.G.\& Lenox, M.J.(2014).Exploring the sociocultural determinants of de novo versus de alio entry in emerging industries. Strategic Management Journal, 35(13),1930-1951.

63. Zhang,Q.\&Fan,J.H.(2013).Focus on the Development of Strategic Emerging Industries in China-Based on SWOT Analysis. International Journal of Business and Social Science, 4(16), 232-239.

64. Zhou,Y.(2015).How public demonstration projects affect the emergence of new industries: an empirical study of electric vehicles in China. Innovation: Management, Policy \& Practice.15(2), 1-23. 